Arhe XVIII, 36/2021

UDK 111.852 Huserl E.

159.954

DOI https://doi.org/10.19090/arhe.2021.36.153-175

Originalni naučni rad

Original Scientific Article

TANJA TODOROVIĆ ${ }^{1}$

Univerzitet u Novom Sadu, Filozofski fakultet

\title{
ESTETIČKA ULOGA FANTAZIJE I NOVI STATUS SLIKE KOD HUSERLA
}

Sažetak: Za Huserla pojam fantazije ima mnogostruko značenje. Estetička uloga fantazije je samo jedna od funkcija koju on ispituje u transcendentalnoj analizi čiste svesti. Huserl će porediti imaginaciju i fantaziju. U svojoj analizi on izbegava tradicionalni pojam uobrazilje, Einbildungskraft, i umesto toga se koristi pojmom Phantasie. Novo razumevanje medijacijske uloge slike u perceptivnim i re-prezentacijskim strukturama svesti će omogućiti ovu razliku. On nema sistemski razvijenu estetičku teoriju, ali posredstvom transcendentalno-fenomenološke pozicije razvija posebno mesto estetičke refleksije u strukturi svesti. Pokazaće se kako Huserl razlikujući fantazijsku aprehenziju od perceptivnog i reprezentacijskog predstavljanja otvara polje za estetiku kao slobodan režim. Time omogućava da se tradicionalna ideja dijalektike razvije u novom pravcu i gradi metodološki fundament za strukturalističku analizu fenomena slike i tela.

Ključne reči: estetika, fantazija, imaginacija, slika, strukturalizam, transcendentalna fenomenologija, telo

\section{UVOD: HUSERL I AKTUALNOST TRANSCENDENTALNO- FENOMENOLOŠKE POZICIJE}

Huserl ispituje pojam fantazije na temelju transcendentalne analize čiste svesti, pokazujući da se njena funkcija ne ograničava samo na estetičku, niti bilo koju drugu partikularnu ulogu, nego da ovaj pojam

\footnotetext{
${ }^{1}$ E-mail adresa autorke: tanja.todorovic@ff.uns.ac.rs
} 
može da ima mnogostruko značenje. Zbog toga je otežan pristup izdvajanju čisto estetičke uloge ovog pojma, posebno što se kroz njegove analize dekonstruiše tradicionalno razumevanje ovog fenomena. Za razliku od Kanta koji analizirajući formalnu podelu subjektivnosti nalazi mesto uobrazilje u području između čulnosti i mišljenja, te zasniva estetiku po ugledu na naučni ideal, Huserl samo usputno pominje kako bi se na temelju čiste nauke subjektivnosti moglo reflektovati ,umetničko delo“ i koji su subjektivni uslovi mogućnosti za jednu takvu analizu. Ipak, možda nedostatak konačne refleksije o poreklu estetičkog suđenja nije nužno i nedostatak Huserlove filozofske refleksije. Možda upravo ovu manjkavost njegove analize možemo posmatrati kao prednost njegove filozofske pozicije koja kroz transcendentalnu analizu daje jednu dekonstrukciju ranije estetike i omogućava podlogu za autore koji će definisati „kraj estetike“, a po ugledu na moderni ideal naučnosti. Tako je Bimel već u analizi Kafkine pripovetke veličao najavu kraja moderne metodologije koja je estetiku podvodila kroz formalističku racionalističku teoriju:

„Slijedeće su analize pokušaj da se umjetnost razumije, to jest protumači, s aspekta filozofije. Epoha u kojoj se tretiranje umetnosti reduciralo na estetičko promatranje završena je, što doduše, ne znači da se ne možemo u nju uvek iznova vratiti, budući da se ta vrsta pristupa umjetnosti naizgled izravno nameće, a $\mathrm{k}$ tome nam je veoma bliska te postavlja promatraču najmanje zahteve."2

Da bismo razumeli pravilno estetičku ulogu fantazije kod Huserla, prvo treba da položimo račune o njegovoj metodologiji koja pokazuje da je šira uloga fantazije mnogo obuhvatnija od teorije suđenja o umetničkim delima. Huserl pre svega ispituje ulogu fantazije u transcendentalnoj strukturi subjektivnosti, kako bi naknadno pokazao sve njene mnogostruke primene na posebna područja „objektivne realnosti”. To znači da se fantazija ne redukuje na estetičku ulogu, već da govori o mnogostrukoj ulozi fantazije i mnogostrukim sferama na koje se ona odnosi. Zarad praktičnosti analize mi ćemo se usmeriti na estetičku

${ }^{2}$ Podv. autor. Biemel, Walter. Predgovor u: Filozofijske analize moderne umjetnosti, prev. N. Čačinović-Puhovski, Prosveta, Zagreb, 1980., str. Xii. 
ulogu fantazije i njen odnos sa pojmom imaginacije u ovom radu, dok ćemo o mnogostrukoj i široj ulozi samo usputno govoriti kako bismo dali širi nacrt Huserlove transcendentalne fenomenološke pozicije.

Iako se Huserlova filozofska pozicija prvenstveno bavi analizom pojmova koji tek naknadno omogućavaju refleksiju umetničkog dela, u filozofskoj refleksiji ne može da nam promakne pokazivanje metodološke sličnosti između „nove“, „mlade“ umetnosti u nastajanju i fenomenološke pozicije. O ovoj sličnosti je govorio već Ortega i Gaset ${ }^{3}$ veoma opširno pokazujući primarno zadivljujuću i neraskidivu vezu između istorije slikarstva i filozofije:

„Vodeći zakon velikih slikovnih varijacija je uznemiravajuće jednostavan. Prvo su se slikale stvari; kasnije senzacije i na samom kraju ideje. To znači da je pažnja umetnika počela da se upravlja prema realnosti; kasnije prema subjektivnosti i na kraju prema intersubjektivnosti. “4

Gaset na pomalo esejski način eksplicira da je došlo do progresivne de-objektivizacije sveta ne samo u filozofskom, nego i u estetičkom smislu te reči. ${ }^{5}$ Huserl će na sličan način govoriti o tome koristeći se terminom subjekt-slika ${ }^{6}$ kako bi objasnio suštinsku ulogu umetničkog dela u subjektivnom procesu aprehenzije. On će praviti razliku između fizičke slike, objekt-slike, i subjekt-slike. ${ }^{7}$ Ovom razlikom on će želeti da istakne slojevito razmatranje objekta umetničkog dela, kao samostalnog subjekta, pokazujući kako se, sa jedne strane,

${ }^{3}$ Uporedi: Prole, Dragan. Jednakost nejednakog, Izdavačka knjižarnica Zorana Stojanovića, Sremski Karlovci-Novi Sad, 2018, str. 236.

${ }^{4}$ Prev. i podv. autor. Gasset, José y Ortega. Sobre el punto de vista en las artes. Revista de Occidente, Madrid, 1929., p. 129. Opširnije u: Todorović, Tanja. „Fantazija i stvaralaštvo u Gasetovoj filozofiji“", u: Arhe 33 (2020): 221-242.

${ }^{5}$ On upravo ispituje novi status „slike“ poredeći fenomenologiju i savremeno slikartsvo u jednoj fenomenološkoj analizi modfikacije i aberacija ovog pojma kroz istoriju. Uporedi: Ćipranić, Miloš. "Fantasmas mudos: una nota sobre la pintura." Escritura e Imagen 15 (2019): 345-355, p. 354.

6 Uporedi: „Bildsujet“ u: Husserl, Edmund. Phantasie, Bildbewusstsein, Erinnerung Zur Phänomenologie der Anschaulichen Vergegenwärtigungen. The Hague - Boston - London: Martinus Nijhoff Publishers, 1980, str. 120.

7 „Physisches Bild“, „Bildobjekt”“, Bildsubjekt““, Ibid. 
subjektivnost ugrađuje $\mathrm{u}$ proces interpretacije smisla predmeta, dok sa druge, samo delo postaje slobodni subjekt koji diktira horizont i mogući pravac interpretacije za subjektivnost.

Transcendentalna fenomenologija nije prva metodologija koja je napravila otklon od moderne estetičke teorije, niti je Huserl eksplicirao jasne stavove o tradicionalnim filozofijama umetnosti. Poziv za novom metodologijom i interpretacijom je bio prisutan već uveliko u samim umetničkim praksama i delima. Iako napredna, Kantova estetička teorija je ostala delimično „zarobljena“ u modernosti. To je naročito vidljivo u njegovom stavu u kome veliča „prirodno lepo“ i u njegovim formalističkim podelama, koje estetiku pokušavaju zasnovati kao „čistu nauku“ koja se bavi posredničkim odnosom uobrazilje između čulnosti i mišljenja, ali koje ne pokazuju samo posredovanje u opštem sklopu duha vremena, kako sopstvenog tako ni istorijskog. Dakako da će ovo već Hegel kritikovati pokazujući medijacijsku ulogu estetike ka najvišim istinama apsolutne duhovnosti. Bimel upravo pokazuje kako je on uspeo da pomiri ideju negacije onog čulnog sa utemeljenjem njenih oblika $u$ duhovnim formama. Ovo pomirenje između čulnog, razumskog i duhovnog je zadatak same umetnosti. A način tog pomirenja se odvija upravo preko fantazije:

„Fantazija je sposobnost koja omogućava pomirenje razumskog i duhovnog oblika. Fantazija je sposobnost odomaćena u čulnom elementu, ali se ipak izdvaja iz njega i stoji na raspolaganju samom duhu; element slobode koji igra vralo važnu ulogu u fantaziji predstavlja duhovni momenat ovog elementa.“ ${ }^{\text {(8 }}$

Pored usvajanja određenih Hegelovih uvida Bimel će pokazati granice njegove estetičke teorije. On će se, naime, složiti sa Hegelom da „najava kraja umetnosti i estetike“ znači i kraj posmatranja umetnosti kao apsolutne forme duhovnih tvorevina čija je primarna težnja usmerena ka najvišim istinama stvarnosti. On dovodi u prisutnost novu egzistencijalističku ravan u analizu umetničkih dela pokazujući da se uloga umetnosti ne ogleda samo u teorijskom-refleksivnom odnosu.

\footnotetext{
${ }^{8}$ Prev. i podv. autor. Vidi: Biemel, Walter. "La estética de Hegel." Convivium (1962), p. 154.
} 
Naime, uloga umetnosti mora biti i egzistencijalistička, ne samo da se pita o istinitosti i neistinitosti predmeta, nego o smislu ili besmislu ljudske egzistencije $i$ tvorevina $u$ svetu života. U duhu te kritike analizirajući Kafkine pripovetke, čija analiza ne može da se svede na puku kritiku društvenosti, Bimel pokazuje kako je na scenu stupilo tumačenje koje se odnosi i na smisao života pojedinca i njegovu ulogu ne samo u sistemu društvenosti, nego u kontekstu životnih vrednosti uopšte. Možda je najbolji primer za ovu analizu Kafkina pripovetka Umetnik u gladovanju koja obuhvata estetičku, filozofsku i egzistencijalnu ravan. Bimel naglašava kako je ova pripovetka odraz onoga što dolazi, u umetnosti prestaje da bude akcenat na proizvodnji umetničkog dela od autorskog rada samog umetnika. Ideja određene negacije i proizvodnje koju je razrađivala idealistička estetika kod umetnika koji gladuje stupa u drugi plan, i performativno izvođenje nekoga ko ne stvara, nego ,posti“ $i$ odriče se materijala i materijalnog stupa u prvi plan. Postaje jasno da se njegova uloga kroz vreme menja, i da način na koji ga publika doživljava kroz vreme biva raznolik. Ovde se svakako provlači pitanje egzistencijalne uloge umetnosti koja nikada nije bila samorazumljiva, ali koja u savremenosti postaje posebno upitna. ${ }^{9}$

Tako Bimel zaključuje da za Kafku novi status umetnosti nije takav da ona ukida sam život i da se postavlja iznad njegovih formi, nego upravo da se probija kroz aporije života koji se u nedostatku apsolutne istinitosti kreće konstantno između ličnog smisla i besmisla, kao i pitanja određenja sopstva u „očima drugih“ koji su suštinski nezainteresovani za propadanje umetnika, koji može biti bilo ko od nas, i onih koji u ovoj pripoveci predstavljaju publiku:

„Ljudi su se susreli sa neobičnom idejom da se od njih može očekivati da se u vremenima poput ovih zainteresuju za umetnika u gladovanju, i sa ovim susretom presuda je izrečena protiv njega. Mogao je postiti koliko je mogao, i to je i učinio; ali ništa ga sada nije moglo spasiti, ljudi su prolazili pored njega،“"10

\footnotetext{
${ }^{9}$ Biemel, Walter. Filozofijske analize moderne umjetnosti, str. 42.

${ }^{10}$ Kafka, Franz. „A Hunger Artist“, in: The Complete Stories, Schocken Books Inc., New-York, 1971., p. 177.
} 
Opasnost ljudske egzistencije, kako lične tako i kolektivne, leži u stalnoj mogućnosti zapadanja u besmisao, koja se dakako razume u kontekstu savremene najave o „smrti boga“ koja je u tradicionalnom smislu imala ulogu da obezbedi tu „najvišu istinu“ kao „razlog življenja“. Ipak, razobručavanje istine koje je Hegel već najavio, u savremenosti postaje sve izraženije dok na scenu stupa skepticizam usled pluralizma novih filozofskih škola, struja i pravaca. To je Huserla još u ranijim delima navelo da traga za jedinstvenom idejom naučnosti koja će moći da razreši aporije savremenog života, kako bi se prevazišao skepticizam i nepoverenje koje stoje u osnovi same subjektivnosti. ${ }^{11}$ Ranija ideja stroge nauke se preobražava vremenom $u$ projekat zasnivanja transcendentalne fenomenologije koja prevazilazi granice i metodologiju moderne naučnosti. Huserl želi da pokaže da je ideja naučnosti starija od zasnivanja posebnih nauka, i želi da se vrati originarnoj ideji nauke, kakva je postojala još u grčkoj filozofiji. Transcendentalni projekat univerzalne nauke o subjektivnosti bi to trebalo da mu omogući. Ipak, u ovim istraživanjima mi nećemo naići na klasifikovane i formalizovane podele „određenih grana“ posebnih nauka i polja istraživanja kod Huserla. On upravo pokušava da prevaziđe racionalistički formalizam mišljenja i empiristički psihologizam, te da završi projekat koji je Kant već počeo. U ovoj analizi dakako ne ostaje prostora za zasnivanje estetike kao posebne naučne discipline.

$\mathrm{Na}$ temelju analize čiste subjektivnosti, mi ipak možemo da pokažemo kako se Huserl odnosi prema samom umetničkom delu i novoj ulozi koju imaju umetnici. On pokazuje da mora da postoji „unutrašnja logika“ svesti koja omogućava sve posebne grane naučnosti, i da kriterijum razlike ne treba tražiti samo u pukoj spoljašnjosti nego i u unutrašnjoj metodologiji koja je omogućava. Tako ispostavlja da je ta unutrašnja logika preduslov svake druge refleksije, uključujući tu i

${ }^{11}$ U delu Filozofija kao stroga nauka Huserl već pokazuje ono što će kasnije eksplicirati u Krizi a to je da se ona ogleda u sve većem rasparčavanju nauka, koje naivno veruju u apsolutnu istinitost naturalističke pretpostavke o materijanoj osnovi realnosti u kojoj subjektivnost ima tek sekundarnu ulogu. Poredi: Husserl, Edmund. Philosophie als strenge Wissenschaft. Vittorio Clostermann, Frankfurt am Main, 1965, s. 33. 
suđenje koje se odnosi na analizu umetničkih dela. On se zbog toga vraća starogrčkom zasnivanju logike $i$ ontologije pokazujući primarni smisao izraza reči „logos“ koja podrazumeva „zbiranje oko nečega“ i „izlaganje i tumačenje“ (na osnovu nečega). ${ }^{12}$ Svakako valja voditi računa o Huserlovom mnogoznačnom korišćenju termina logos. Kada postavlja zahtev da se logika postavi u osnovu subjektivnosti, on pod time ne misli sedimentirani ostatak moderne nauke logike. U sličnom maniru se služi i pojmom Begründung, koji ne podrazumeva, kako stoji u engleskom prevodu, ,grounding" koje bi doslovno značilo utemeljenje, nego on taj pojam koristi kao „obrazlaganje“, izvođenje i tumačenje stavova. ${ }^{13}$ Smisao termina logosa i nemačkog termina Begründung je važno razumeti u kontekstu „tumačenja“ i ,izlaganja“ upravo jer Huserl želi da izbegne novovekovno definisanje subjekta kao pod-ležećeg, kao supstancije koja utemeljuje sve drugo na apodiktičan način i za koji je najadekvatnija deduktivna metoda. ${ }^{14}$ Samozaborav nauke, prema ovoj analizi, ogleda se u predstavi njihove apsolutne autonomije, u relacijama koje se razdvajaju u interdisciplinarnoj sferi i tome što je logika postala subordinirana samoj naučnoj metodologiji, dok bi za Huserla to trebalo da bude obrnuto. Fenomenologija kao transcendentalna filozofija ima zadatak da povrati izvorni filozofski smisao logike. Povratak izvoru je uvek iznova vraćanje i predstavlja jedan aktivan proces. Huserl inkorporira regresivan arheološki korak od aktivne dimenzije svesti ka pasivnoj sedimentaciji koja je omogućava. Jedino u povratku na staro i

\footnotetext{
${ }^{12}$ Husserl, Edmund, Analyses concerning passive and active synthesis: Lectures on transcendental logic, Kluwer Academic Publishers, Dordrecht- BostonLondon, 2001., str. 8.

${ }^{13}$ Uporedi: Husserl, Edmund, Phantasie, Bildbewusstsein, Erinnerung Zur Phänomenologie der Anschaulichen Vergegenwärtigungen. The Hague Boston - London: Martinus Nijhoff Publishers, 1980., §48 i Husserl, Edmund. Phantasy, image consciousness, and memory (1898-1925).Vol. 11. Springer Science \& Business Media, 2006., §48.

${ }^{14}$ Ovom razlikom se već Huserlova studentkinja Zagroka Mićić služila, a prof. dr Dragan Prole je istakao njenu važnost u kontekstu Huserlovog otklona od kartezijanizma. Uporedi: Prole, Dragan. Predgovor u: Huserl, Edmund. Kartezijanske meditacije, prev. Prole D., Izdavačka knjižarnica Zorana Stojanovića, Sremski Karlovci - Novi Sad, 2020, str. 11.
} 
kroz pasivnost može da se dođe do osnove tradicionalne logike i on smatra da kritika idealnih struktura razumske logike nije zadatak same logike, već transcendentalne estetike.

Namera ovog istraživanja jeste da se istaknu osnovni momenti estetičke uloge fantazije, koji, sa jedne strane, izdvajaju estetiku iz modernog ideala naučnosti, dok sa druge, omogućavaju novoj umetnosti da sebe ostvari kao slobodno, nezavisno polje, poseban režim delovanja. Sa fundamentalnom razlikom između perceptivne (Gegenwärtigung), reprezentacijske (Vergegenwärtigung) i fantazijske aprehenzije (Phantasie), Huserl omogućava polju imaginacije da bude višestruko nezavisno. Polje fantazije prestaje da ima posredničku ulogu $u$ subjektivnim strukturama između čulnosti i mišljenja kakvu je imalo kod Kanta, ali isto tako postaje nezavisno od vladajuće etape opštih vrednosti duha vremena, od vladajuće ideologije. Tako umetnost prestaje da bude posrednik ka vladajućim vrednostima. U tom duhu Gaset zaključuje kako deluje kao da nova, mlada umetnost ide protiv čoveka, protiv živih oblika, protiv same stvarnosti. ${ }^{15}$ Huserlova analiza je omogućila temelj za razumevanje novih umetničkih pokreta. Umetnost gubi svoj reprezentacijski karakter, prestaje da bude ,slika određene stvarnosti” i postaje slobodno polje delovanja koje vrednosti više ne crpi iz samog sveta, nego iz života koji postaje vrednost za sebe. Tako se Huserlova transcendentalna analiza estetičke uloge fantazije može uporediti sa Bimelovom dijagnozom nove uloge filozofije umetnosti, čija primarna namera nije teorijskog karaktera u traženju najviše istinitosti stvarnosti, nego se pita o smislu i besmislu, te vrednostima na kojima je život utemeljen.

\section{FANTAZIJA, IMAGINACIJA I NOVI STATUS SLIKE}

Huserlu se zamera što krizu nije pokazao iz praktičkoekonomskog konteksta, te što se bavio epistemološkim problemom nauke. Ipak, za to postoji razlog. Huserl je smatrao da je u osnovi svake

${ }^{15}$ Gasset, José y Ortega. Dehumanizacija umetnosti $i$ drugi eseji, LITTERIS, Zagreb, 2007, str. 35. 
posebne krize, ekonomske, umetničke, političke i naučne jedna ista kriza subjektivnosti i načina mišljenja koja je onda dovela do problema u svim partikularnim sferama $\mathrm{i}$ da je rasparčanost posebnih disciplina samo posledica zaboravljanja prvobitne ,istorijske pukotine“ u povesnom procesu sedimentacije. Na sličan način će i Gaset govoriti o ,pobuni masa“ ne nužno kao jednom političko-ekonomskom problemu, nego kao o subjektivno-ontološkom fenomenu koji se različito ogleda u svim posebnim sferama. Kako on pokazuje, na scenu je stupio „čovek mediokriteta“. ${ }^{16}$ I drugi autori poput Roberta Muzila kasnije pišu o čoveku bez osobina u modernom romanu (Der Mann ohne Eigenschaften), dok će savremena kriza uveliko biti na različite načine predstavljena u pokretima nove, mlade, avangardne umetnosti.

Huserl će pokušati u svojim analizama estetičke uloge fantazije da napravi otklon od moderne razdeobe čulnosti i da zasnuje novu teoriju suđenja o umetničkim predmetima. $U$ analizi subjektivnih načina aprehenzije i otklonu od Brentanovog psihologizma, fenomenolog želi da pokaže da kriterijum razlike u suđenju o predmetima, ne može biti $u$ samom predmetu, nego i načinu na koji ga subjekt zahvata. Iako je veličao Kanta kao povesnog prethodnika transcendentalne nauke o subjektivnosti, Huserl će napraviti otklon od njegovog razumevanja pojma „uobrazilje“. On izbegava klasičnu nemačku upotrebu termina Einbildungskraft, i umesto toga se koristi pojmom Phantasie. Mnogo je razloga zašto Huserl izbegava tradicionalno razumevanje pojma uobrazilje, imaginacije i unutrašnjeg čula. Još u Idejama I, termini imaginacije i fantazije kod njega su jasno razdvojeni. ${ }^{17}$ Sa jedne strane,

16 „Tenemos, pues, que la vida del hombre medio está ahora constituida por el repertorio vital que antes caracterizaba sólo a las minorías culminantes." $\mathrm{u}$ : Gasset, José y Ortega. La rebelión de las masas. Espasa-Calpe, Madrid, 1964, p. 17.

17 Husserl, Edmund. 1976. Ideen zu einer reinen Phänomenologie und phänomenologischen Philosophie. Erste Buch. Allgemeine Einführung in die reine Phänomenologie. Husserliana III/1. Edited by Karl Schuhmann. The Hague: Martinus Nijhoff. Translated by F. Kersten as Ideas Pertaining to a Pure Phenomenology and to a Phenomenological Philosophy, in Edmund Husserl Collected Works, vol. II (The Hague: Martinus Nijhoff, 1983). [HuaIII/1], §70. 
fantazija je oblik predstavne svesti, modifikacija čiste re-prezentacije (Vergegenwärtigung), i iako prisutna, pojavljuje se uvek u formi neaktualnosti za razliku od percepcije i prezentacije (Gegenwärtigung). Sa druge strane, termin imaginacija shvata se u mnogo širem kontekstu. U njemu se ističu sposobnosti predstavljanja objekta, kao kompleksni oblik re-prezentacijske svesti koji se ne odnosi samo na umetnička dela, nego mogućnost predstavljanja i medijacije $u$ širem smislu te reči. ${ }^{18}$ Pojam medijacije Huserl razumeva u otklonu spram Hegelove spekulativne fenomenologije, tako predstava, slika (lat. imago), nije samo jedan apstraktni aspekat koji nastoji da razrešava protivrečnosti apsolutne ideje u duhovnom traganju za „logikom pre stvaranja sveta“, nego je slika posrednik između subjekta i sveta koji se ne razrešava nužno kroz prizmu apsolutne svesti, koja može da ostane opskurna, zamućena, nedorečena i zapravo zauvek nerešiva, kao što i sam predmet može da ostane ne-otkriven do kraja. Huserl to objašnjava kroz mogućnost sukoba percepcijske i re-prezentacijske aprehenzije, na koju je subjektivnost osuđena $u$ svom traganju za znanjem. ${ }^{19}$ Polje fantazijske reprezentacije je, kako je to već Bimel istakao, slobodno - to znači da je način na koji fantazija konstituiše objekat delimično nezavisan od percepcije i re-prezentacije koja se odnosi na sećanja. Ipak, iako polje fantazije ima sopstvene moduse funkcionisanja, ono ne može biti u potpunosti nezavisno od temporalne strukture svesti i ne može da negira senzibilni i percepcijski svet. Postoji istovremeno jedinstvo ali i mogućnost sukoba između perceptivnog i fantazijskog polja. Kako se pokazuje, ova dva polja ne mogu intuitivno da se zahvate u jedinstvu zbog različitog načina na koji im se daje sam predmet: „Situacija je potpuno drugačija ako se razmatraju perceptivno i fantazijsko polje. Ova dva nikako ne mogu da se zahvataju zajedno.“20 Možda bi najbolji

${ }^{18}$ Uporedi: Katz, Azul Tamina. "Toward a Husserlian Foundation of Aesthetics: On Imagination, Phantasy, and Image Consciousness in the 1904/1905 Lectures." The Journal of Speculative Philosophy 30.3 (2016), pp- 339-351., p. 342 .

19 Husserl, Edmund, Phantasie, Bildbewusstsein, Erinnerung Zur Phänomenologie der Anschaulichen Vergegenwärtigungen, s. 76; §36, ff. 10.

${ }^{20}$ Prev. i modf. autor. Ibid, s. 75.\$36, ff. 30. 
primer u prilog ovoj konstataciji mogla da bude osoba u koju je neko zaljubljen. Sa jedne strane, onaj koji je zaljubljen formira fantastičnu, idealnu sliku o predmetu svoga obožavanja. Ta slika često nije u saglasnosti sa onim kako se neko realno pojavljuje. Vremenom dolazi do sukoba između fantastičnog i perceptivnog uvida koji ostaje otvoren za pitanje kako će se razrešiti.

U transcendentalnoj svesti se ispostavlja kako subjektivni modusi odnosa prema predmetu igraju presudnu ulogu u konstituisanju istog. Tako Huserl pokazuje da „naivno“ verovanje u istinitost predmeta pre ispitivanja modifikacija njegovog pojavljivanja valja staviti $u$ zagrade. To znači da iako modus „verovanja“ koji je osnova saznajne svesti predstavlja primarni subjektivni odnos prema predmetu, da treba imati $\mathrm{u}$ vidu njegove modifikacije poput sumnje, skepticizma $\mathrm{i}$ neizvesnosti. Oni se najčešće aktiviraju u preklapanju dva načina aprehenzije, perceptivnog i re-prezentacijskog odnosa svesti, kao i treće mogućnosti koja se odnosi na estetičko suđenje o predmetu, a reč je o fantazijskoj aprehenziji. Pošto je prvi stupanj odnosa prema predmetu suđenje o njemu kao fizičkom objektu, primer kojim se Huserl najčešće služi da bi istakao mogućnost nesaglasnosti među intencionalnim zahvatanjima predmeta jeste primer voštane figure. Naime, on pokazuje da kada ispred sebe imamo verno urađenu voštanu figuru, u našem susretu sa istom svest može da upadne u modus sumnje te da se dvoumi da li je reč o realnom, pravom fizičkom objektu, ili njegovoj plastičnoj reprodukciji, pitajući se da li je reč o čoveku ili lutki. ${ }^{21}$ Ova dvojba ne pripada samom objektu, niti percepciji koja ima modalitet aktualnosti. Naivna izvesnost nam ne govori ništa o različitim mogućnostima suđenja. Neophodno je uvideti da sumnja može biti razrešena, da suštini sumnje pripada potreba za verifikacijom i za razrešenjem. Ali dok sumnja traje upitne su obe vrste prezentacijske svesti. Imaginacija ovde nema ulogu tumačenja samog objekta nego prosuđivanja o poreklu njegove egzistencije. Huserlova ideja je da postoje različiti kriterijumi istinitosti u zavisnosti od toga kojoj vrsti intencionalne analize pripada

\footnotetext{
${ }^{21}$ Husserl, Edmund, Analyses concerning passive and active synthesis: Lectures on transcendental logic, s. 72.
} 
naše suđenje, i da oni ne zavise od samog objekta koji se pojavljuje. Ovo suđenje dakako nije estetičko suđenje, ali nije reč ni o pukoj teoriji korespondencije, i naivnom realizmu, nego o pokazivanju kako je u svaki proces suđenja $\mathrm{u}$ predmetu inkorporiran različit modus subjektivnog odnošenja prema istom, bilo da je reč o verovanju (koje je uvek gradualnog karaktera), sumnji, kritici i dr.

Svaki predmet se za subjekat pojavljuje u formi „slike“, dok je za estetički predmet karakteristično to da je slika koja se udvaja, da je reč o slici koja predstavlja jedan samostalan subjekt koji je istovremeno objekat koji zahvatamo. Za Huserla, predmet ima slojeve. Tako, na primer, određenu sliku kao umetničko delo, ,jedan jedini predmet“, subjekat kroz svoju intencionalnu analizu zahvata na tri različita načina. To se dešava zato što svest ima mogućnost različitog načina aprehendiranja istog objekta. Već je napomenuto da Huserl razlikuje tri uloge slike: fizičku sliku (Physisches Bild), objekt-sliku (Bildobjekt), i subjekt-sliku (Bildsujet). U ediciji koja se bavi pre svega analizom imaginacije i fantazije, Husserliana XIII, on se koristi i različitim terminima za obeležavanje objekta u zavisnosti da li je u pitanju predmet koji se odnosi na percepcijsku analizu, senzualni objekt, ili je u pitanju predmet fantazije koji nema integralno jedinstvo sa percepcijskom svešću, figment. Ove reference su za njega presudne jer smatra da postoji fundamentalna razlika za svest $\mathrm{u}$ načinu na koji zahvata različite predmete i njenoj unutrašnjoj temporalnoj strukturi.

U analizi određenog umetničkog dela, pokazuje se da fizička slika, objekt-slika i subjekt-slika mogu da budu u konfliktu, iako se odnose na isti predmet. Jedan od primera kojim se Huserl koristi u tom kontekstu je primer fotografije na kojoj je predstavljena osoba. On pokazuje da u primarnoj analizi mi vidimo fotografiju kao fizički objekt, nešto što je, na primer, okačeno na zidu - ovde je reč o perceptivnoj svesti i modu aktualnosti za nas, reč je o fizičkoj slici. Ipak, tek kada uđemo u analizu objekta možemo da vidimo da se on nama re-prezentuje kao samostalan, da ima neki svoj način predstavljanja za nas - na primer, primećujemo da je reč o umetničkom delu koje nas podseća na neku fotografiju, umetnički objekt, ono se nama daje na potpuno određen način, mi ga zahvatamo prema određenim pravilima, reč je o objekt-slici. 
I na samom kraju, fantazijska aprehenzija zahvata predmet kao subjektsliku - to znači da uviđamo da slika, iako za nas data kao fizički i objektivan predmet, predstavlja samostalan subjekt koji u sebi nosi određenu strukturu smisla koja ne može biti otkrivena na prvi pogled. Tako ova vrsta aprehenzije zahteva posebno raspoloženje, jednog nepristrasnog gledaoca koji neće suditi samo o formi i položaju objekta već i onome što slika predstavlja, reč je o udvajanju koje se događa u slici slike. Iz jednog fenomenalnog prikaza na slici, u ovom slučaju osobe, možemo da zaključimo na njenog referenta: samu osobu, strukturu u kojoj je slika nastavlja, šta je detaljima umetnik želeo da izrazi, zašto je baš iz određenog ugla nešto predstavio i dr.: „Fotograf, ako je posebno dobar, može da nam predstavi samu osobu (kroz sliku) “'22. Huserl čak pokazuje kako postaje u ovom kontekstu važan svaki detalj na slici, uključujući i ram čiji je zadatak da odvoji realno od idealnog, prednji plan (fizički objekt) od pozadine umetničkog dela (slike-subjekta). ${ }^{23}$ Cilj ovih razmatranja je da se pokaže da postoje različiti načini aprehendiranja objekta i da je perceptivna svest samo prvi stupanj zahvatanja objekta koja predstavlja prezentacijsku svest u kojoj se objekat sam daje subjektu na tačno određen način. Sa druge strane, imamo re-prezentacijsku, imaginacijsku svest koja može biti mnogostruka. Fantazija je oblik re-prezentacijske svesti koja nije nužno zavisna od samog davanja objekta, kao što je reč u senzibilnosti i sećanju, već ima svojevrsnu slobodu u konstituisanju, tumačenju i obrazlaganju predmeta. U fantaziji je reč o tome da se sa jedne strane, približimo verno subjektu-slici, skrivenom smislu objekta umetničkog

22 Husserl, Edmund, Phantasie, Bildbewusstsein, Erinnerung Zur Phänomenologie der Anschaulichen Vergegenwärtigungen, s. 52, ff. 10.

${ }^{23}$ Ova Huserlova analiza je svakako dala temelj za Hartmanovo zasnivanje estetičke teorije koja se bavi slojevima predmeta više u objektivnom, manje u transcendentalnom maniru. Ipak, u analizi samog umetničkog dela primećuju se određena preklapanja. Tako Hartman razlikuje slojeve posmatranja umetničkog dela. Za razliku od Huserla koji govori o fizičkoj slici, i objekt-slici koja može da bude i pokretnog karaktera (film), Hartman govori o prednjem planu, a subjekt-slike je u suštini pozadina koja ga na određen način upotpunjuje, omogućava i daje mu celinu. Uporedi: Hartman, Nikolaj. Estetika, Dereta, Beograd, 2004., str. 87. 
dela, ali i da damo svojevrsno tumačenje i doživljaj koji je nezavisan od samog dela, u koji je ugrađena sama subjektivnost, ili intersubjektivno tumačenje prikaza koji je dat.

Huserl naglašava da čistu imaginaciju (fantaziju) treba razlikovati od imaginacijske svesti. Ona se temelji na distinkciji između stvaralačke uloge imaginacije koja se odnosi na čistu fantaziju i refleksivnog karaktera imaginacije koji se odnosi na interpretaciju. U oba slučaja je reč o formi re-prezentacije (Vergegenwärtigung), od koje su imaginacija i fantazija samo uslovno zavisne, u smislu prethodne datosti predmeta. U oba slučaja je, takođe, reč o neophodnosti prethodne neutralizacije, kako bi se objekat zahvatio kao irealan, kao virtuelan. ${ }^{24} \mathrm{U}$ polju čiste fantazije intendirani objekat nije prisutan $\mathrm{u}$ podležećoj percepcijskoj datosti (na primer jednorog). On je samo uslovno dat u prethodnom iskustvu koje je bilo neophodno za formiranje nove slike. Objekat je figment kome nedostaje sadržajno jedinstvo svesti, i ima egzistencijalni karakter „kao da“ jeste prisutan (als ob). Sa druge strane, imaginacijska svest je „svest o drugosti“ (Bewußtseins des 'Andersseins'), to je svest koja se udvaja, o kojoj je prethodno bilo reči. U njoj je predmet prvobitno dat u podležećoj perceptivnoj svesti (kao umetnički predmet na primer) te ga zahvatamo u skladu sa nezavisnim poljem fantazijske aprehenzije tek naknadno.

Paralelno sa idejom da se od stare napravi nova „originalna“ slika na temelju već postojeće, da se subjekt-slika uvuče ne samo u proces intepretacije već i u proces stvaranja, oživljava nova forma umetničkog stvaranja poznatija kao ready-made. Huserlova ideja je da s jedne strane pokušamo da razumemo strukturu umetničkog dela tako što ćemo da analiziramo sklop smisla u kome je sačinjeno samo delo, ali isto to delo u sadašnjosti, u novoj analizi, interpretaciji i reprodukciji može da dobije potpuno novi sklop i smisao koji stoji u ko-relaciji spram prethodnog smisla. On pokazuje da u svojoj osnovnoj funkciji fantazija ima ulogu reprodukcije, njena relacija u odnosu na samu aprehenziju

24 Više o ovoj razlici: De Warren, Nicolas. "Towards a phenomenological analysis of virtual fictions." in: Metodo. International Studies in Phenomenology and Philosophy 2.2 (2014), pp. 108-109. 
svesti je ne-aktualna, i ne-prisutna (Nicht-da). ${ }^{25}$ Kada je reč o čistoj fantaziji, njen zadatak je stvaranje novog samo u uslovnoj relaciji spram sadašnjeg. To znači da iz ove perspektive stari objekat može da dobije potpuno novi smisao u novom strukturnom sklopu događaja. Sam pojam reprodukcije ovde kod Huserla prestaje da bude nešto negativno. Tako ranija platonistička ideja kopije koja stoji ontološki niže u odnosu na „original“ dobija drugi smisao. Za Huserla re-prezentacijska svest funkcioniše na temelju reprodukcije. Drugim rečima, bez reprodukcije ne bi bilo ni memorije, ni sećanja, ni anticipacije, a samim tim ni stvaranja. Reprodukcija je način na koji svest konstituiše predmet onda kada on nije prisutan. Dok se impresija odnosi na individualno iskustvo, re-produkcija predstavlja modifikaciju tog iskustva, i onda može da bude ili memorijskog ili fantastičnog karaktera. ${ }^{26}$ Ona u fenomenološkom kontekstu dobija novo značenje koje može da ima pozitivan karakter, u kome je smisao subjekta utkan u konstituciju predmeta bilo da je reč o njegovoj kritici već postojeće slike, ili apsolutnoj afirmaciji realnosti. Tradicionalni pojmovi poput, slike, re-produkcije, kopije, relacije i negacije u transcendentalno-fenomenološkoj analizi dobijaju potpuno novi smisao. Iz subjektivne perspektive oni se u konstituisanju svesti pokazuju kao nužni momenti definisani na potpuno novi način. Pokazuje se da proces stvaranja novih sadržaja na temelju čiste fantazije, kao i proces interpretiranja starog na temelju imaginacijske svesti, predstavljaju jedno slobodno polje igre, koja nema spoljašnji kriterijum istinitosti i vrednosti koji bi mogla naći bez samih vrednosti koje im subjektivnost kao takva zadaje.

\section{FENOMENOLOGIJA NA PUTU KA STRUKTURALIZMU, REFRAKCIJA TRADICIONALNE DIJALEKTIKE}

Transcendentalno-fenomenološka analiza subjektivnih uslova zahvatanja predmeta samo naizgled ostaje nedorečena kada je reč o

25 Husserl, Edmund, Phantasie, Bildbewusstsein, Erinnerung Zur Phänomenologie der Anschaulichen Vergegenwärtigungen, p. 167, ff. 5.

${ }^{26}$ Isto, p. 331, ff. 15. 
objektivnoj analizi realnosti. Huserlova fenomenološka pozicija ne ostaje formalistička u smislu u kome je to bio moderni racionalizam. On je upravo pokušao da kritikuje raniju ideju klasične podele nauke i racionalističke objektivističke konstrukcije. ${ }^{27}$ Ono što je specifično u ovoj metodologiji je već prvi korak, epoché, koji govori o potrebi da se u kriznom periodu „ide korak unazad“, da se pokušamo vratiti na početnu tačku krize, na varijaciju od izvornog smisla koja se događala u istoriji filozofije dok nije došlo do sve većeg otuđenja od prvobitne ideje naučnosti koja je kod Aristotela data u ideji prve filozofije. Ipak, inspiracija koju Huserl nalazi u tradicionalnim naukama ne znači za njega nužno mogućnost povratka na staro. Ono što je slično Hegelu i Huserlu jeste jedna afirmacija povesne prošlosti, jedno priznavanje rezultata svojih prethodnika $\mathrm{i}$ afirmisanje njihovih osnovnih stavova pokazujući kako su oni bili nužne preteče nadolazeće filozofske pozicije. U ovom kontekstu su za transcendentalno-fenomenološki subjektivizam najviši značaj imali Dekart i Kant.

Iako priznaje rezultate svojih prethodnika, Huserl tradicionalnim pojmovima u sklopu nove metodologije ,povlačenja u subjektivnost“ daje i novu terminologiju. Tako tradicionalni pojam „negacije“ koji je u idealizmu imao i funkciju „određene negacije“, poietike i proizvodnje, ili dijalektičke afirmacije u kritici, $\mathrm{u}$ fenomenološkoj analizi dobija novi značaj. Za Huserla pojam negacije nema više ovu ulogu, jer on ovaj termin koristi kako bi pokazao subjektivne uslove za unutrašnju promenu i varijaciju same svesti, te se ne odnosi na modifikaciju sadržaja nego na izlaganje onoga što ih uslovljava kao takve: „Negacija je modifikacija svesti koja se kao takva pokazuje u skladu sa sopstvenom suštinom." ${ }^{\text {"28 }}$ Za njega ovaj pojam nema više dijalektičku ulogu nadgradnje, ukidanja i očuvanja, već ulogu modifikacije, kontrasta i varijacije koji omogućava ne samo analitičku ulogu svesti, nego i anticipacijsku, i futurističku

$27 \mathrm{Tu}$ pre svega kritikuje Lajbnica. Uporediti: Husserl, Edmund. Erste Philosophie, Felix Meiner Verlag Hamburg, 1992, s. 182.

${ }^{28}$ Husserl, Edmund, Analyses concerning passive and active synthesis: Lectures on transcendental logic, str. 71. 
ulogu projekcije, ispitivanja mogućnosti i analiziranja opcija na temelju sadašnjeg stanja stvari. ${ }^{29}$

Kao što pojam negacije u ovim analizama dobija novo određenje, tako se menja smisao i razumevanje tradicionalno shvaćenog pojma slike. Slika dobija mnogostruko, vrlo složeno određenje, upravo jer ne predstavlja nešto naprosto objektivno, niti subjektivno, već je reč o tome da je ona posrednik u svim različitim stupnjevima i slojevima zahvatanja predmeta od strane aktive svesti. Slika koja predstavlja virtualni objekat u Huserlovoj analizi nije naprosto činjenična datost, već je treba shvatiti u slojevima zbog intencionalnosti koja je određuje. Ovo se odnosi na objekte imaginacijske svesti, ali jednako tako i na objekte koji su produkt čiste imaginacije, mašte i fantazije. Reč je o konglomeratu smisla, fenomenima koji nose u sebi različite slojeve objektivnosti koji mogu biti zahvaćeni kao perceptivna stvar, imaginarni predmet ili naprosto simbol. ${ }^{30}$ Upravo će taj višestruki status koji slika zadobija u fenomenološkoj analizi biti predmet kasnijih strukturalističkih analiza koje pokazuju složeni način na koji subjekat zahvata i kreira realnost.

U samoj umetnosti ovi pojmovi takođe dobijaju novi smisao. ${ }^{31}$ Ono što Frankfurtska škola uspeva da usvoji od idealističkog učenja, ali i od fenomenološke analize, jeste mogućnost reverzibilne uloge dijalektike u subjektivnom odnosu prema realnosti. To znači da će kasniji autori insistirati ne samo na objektivnom odnosu statusa sopstvenog vremena čija je uloga subjekta onda samo da ga naknadno reflektuje, nego i o subjektivnim uslovima mogućnosti za jednu takvu vrstu sinteze. Tako će autori poput Ransijera ispitivati granice subjektivizma u sklopu sadašnjosti i njegove povesne koordinate koje ga određuju na tlu iskustva i života za analizu i promenu postojeće

\footnotetext{
${ }^{29}$ Više o tome: Erhard, Christopher, Denken über nichts - Intentionalität und nicht-existenz bei Husserl. Walter de Gryter GmbH, Berlin-Boston, 2014.

30 Uporedi: De Warren, Nicolas. "Towards a phenomenological analysis of virtual fictions." in: Metodo. International Studies in Phenomenology and Philosophy, p. 98.

31 Prole, Dragan. "Redukcija u fenomenologiji i slikarstvu." Годишњак Филозофског факултета у Новом Саду 41.2 (2016): 67-77, str. 71.
} 
realnosti. U analizi umetnosti tako i status „slike“ dobija novi značaj, novu višeslojnu funkciju koju je Huserl u svojoj transcendentalnoj analizi već najavio: „Slika nikada nije jednostavni odraz realnosti. Filmske slike su primarno operacije, relacije između izrecivog i vidljivog, načini da se izvede radnja „pre“ i „posle“, one su uzrok i posledica. Ove operacije zahtevaju različite funkcije-slike, različita značenja sem reči 'slika'.“32 U analizi „,novog statusa slike“ vidimo da je u umetničkom odnosu prema slici važno dopreti do „sedimentiranog“ smisla samog sopstva umetničkog dela, kako bismo ispostavili lanac relacija koji ga je konstituisao. Tako slika nikada nema u realističkom smislu ulogu „korespondencije“ sa realnošću, nego koherencije koju treba razumeti kroz analizu imanentne strukture samog dela. U ediciji Husserliana XIII, u kasnijim tekstovima već možemo da vidimo kako se govori o mogućnosti rascepa između percepcije i re-prezentacije, sećanja i sadašnjosti, i novom statusu koji slika ima u toj medijaciji. ${ }^{33}$

Promena koja je reflektovana u novom statusu slike u teorijskofilozofskom smislu vidljiva je i u praksi same umetnosti. Ransijer smatra da je upravo mesto novog statusa umetnosti u mogućnosti tog reverzibilnog procesa, u vakuumskom prostoru između subjekta i sveta, te da ona ima novi režim pojavljivanja koji je omogućen kroz specifičnu razdeobu čulnog i senzibilnog sveta. On pokazuje da estetika ima svoju unutrašnju politiku koja je nezavisna od drugih režima. Ona ima specifičnu unutrašnju politiku koja se nalazi u tenziji između umetnosti koja je vezana za sam život po cenu samoukidanja (kao što je slučaj sa ranim avangardama) i sa druge strane, u stalnoj je opasnosti da podlegne dominantnom političkom režimu i struji te da mu bude subordinirana. Ipak umetnost se kao takva konstituiše i oformljava u ovoj tenziji u kojoj dobija svoju ulogu i status koji ne može onda da se redukuje na dominantne obrasce sopstvenog duha vremena. ${ }^{34}$ Ransijer, poput

\footnotetext{
${ }^{32}$ Rancière, Jacques. The future of the image.Verso, 2019., p. 6.

33 Husserl, Edmund, Phantasie, Bildbewusstsein, Erinnerung Zur Phänomenologie der Anschaulichen Vergegenwärtigungen, s. 437, ff. 20.

${ }^{34}$ Uporedi: Rancière, Jacques. Aesthetics and its Discontents, Polity Press, Cambridge, 2009., p. 45.
} 
Frankfurtske škole, reverzibilni proces vezuje za kritičku ulogu umetnosti, za mogućnost njene „nesaglasnosti“ sa svetom. On iz dijalektike izdvaja njen negativni momenat koji ide $u$ pravcu razobručavanja realnosti i koji podrazumeva sumnju prema prošlim i sadašnjim vrednostima, te traži sopstveno polje važenja. Ono se u ovom domenu ne shvata u pravcu linearnog kretanja, niti teleološkog istorijskog ispunjenja, već upravo u pravcu rasparčavanja i ograđivanja umetnosti u polju dominantnog režima važenja određenih ideja i vrednosti.

$\mathrm{Za}$ Huserla projekat transcendentalne estetike će samo delimično imati kritički karakter. On će se osvrtati na analizu čulnosti, percepcije i senzibilnog u kontekstu ispostavljanja njihove logike u relaciji sa drugim načinima refleksije subjektivnosti. Zbog toga je njegov primarni zadatak da analizira odnos aktivnih i pasivnih sfera subjektivnosti koje jednako učestvuju u konstituciji predmeta. Rečju, Huserlova fenomenološka pozicija je jednako okrenuta prema prošlosti, kao i prema budućnosti, iako je njen primarni interes da odgovori na izazove sadašnjeg vremena. Zbog toga on, paradoksalno, uspeva da očuva fundamentalnu ulogu tela $\mathrm{u}$ transcendentalnoj filozofiji, koja tradicionalnom još sa Kantom biva ostavljena po strani. Pošto se uloga negacije u kontekstu ove analize menja, i sam pojam kritike dobija novo značenje. Kritika je varijacija svesti koja nastoji da afirmiše ono pozitivno ne samo u sadašnjosti kao da je reč o nadgradnji, nego i o prošlosti koja ima mogućnost reaktivacije u sadašnjem, kako u pozitivnom tako i u negativnom aspektu. Da bi se subjektivnost oslobodila dominacije sadržaja koji nameće već uspostavljeni horizont na temelju pasivne strukture svesti koja samu svest uslovljava u pravcu određene budućnosti, neophodno je stavljanje u zagrade važećih smislova. Tako se događa refrakcija linearnog puta dijalektike, čije kretanje za samu budućnost onda postaje neizvesno i udvaja se u polje čistih mogućnosti iz perspektive jednog transcendentalnog posmatrača. Ono što je karakteristično za Huserla jeste to što se napetosti dijalektike ne razrešavaju preko apsolutnih ideja, niti je oslobađanje od njih ikad u potpunosti moguće. Svest je kao takva uvek u dinamizmu između tri vremenske dimenzije u kojim je njena uloga usmeravanja pažnje presudna za dalji tok realnosti. Tako Huserl 
dijalektiku oslobađa od njene usmerenosti ka ostvarivanju neke spoljašnje svrhe koja bi bila moguća bez subjektivne ugradnje $u$ istu.

Kao što za strukturaliste poput Ransijera postaje presudno važno samo telesno iskustvo, i određivanje granica senzibilnog sveta, tako Huserl pokazuje fundamentalni značaj životnog iskustva i percepcije u odnosu na re-prezentacijski karakter svesti. Konkretno živo telo konstituiše primordijalno iskustvo, i to postaje osnova za sve druge analize koje se odnose na ovu perceptivnu aprehenziju. Tako on pokazuje da ono što je konvencionalno i normativno usvojeno kao „nenormalno“ za samo živo telo i percepciju nema status nečeg negativnog, nego naprosto predstavlja modifikaciju i aberaciju od prethodnog iskustva. To što neko iskustvo nije uopštivo ili je lično, za Huserla ne znači da je „lažno“. ${ }^{35} \mathrm{U}$ transcendentalnoj analizi, iako „subjektivno“, moguće je preispitati „objektivne“ uslove za njegovo konstituisanje. Tako sve dobija smisao i značaj u odnosu na subjektivnost koja konstituiše isti:

„Baš kao što objektivna stvarnost prirode nije činjenica koja postoji sama za sebe i bez ikakve veze sa egom, već je činjenica za ego, naime, tek kroz stvarna i moguća iskustva i verifikacije koje su unapred postavljene u njemu. “36

Ego treba shvatiti uvek već u monadologijskom poretku stvari u kome se on nalazi u svetu, koji pravi otklon od psihologizma pokazujući da se ne ostaje na deskripciji pojedinačne sveti već da se traži jedan ontološki temelj, personalno-komunikacijski prostor života. ${ }^{37}$

Ova metodologija pokazuje i omogućuje ne samo nezavisan status čiste fantazijske aprehenzije i imaginacijske svesti od prethodnih oblika, kao što su percepcijska i reprezentacijska forma, nego omogućava i jedan okvir za razumevanje nove, mlade umetnosti za koju se čini da „ide protiv svog vremena“. Tako Huserlova filozofija ostaje samo naizgled nezainteresovana za život, umetnost i ono političko, dok

\footnotetext{
${ }^{35}$ Husserl, Edmund, Analyses concerning passive and active synthesis: Lectures on transcendental logic, str. 267.

${ }^{36}$ Ibid., p. 268.

${ }^{37}$ Ibid., p. 269.
} 
je primarni cilj ove metodologije bio upravo da pokuša da odgovori na aktualne probleme sopstvenog duha vremena. Za njega nijedan oblik života nije svodiv na drugi, tako ni estetika ne možda bude dominantna u odnosu na druge oblasti subjektivnosti, kao što je to bio slučaj u romantizmu. Prema ovom stanovištu, fenomenologija je nauka koja je pre svega usmerena na ispostavljanje subjektivnih uslova koji će naknadno da ispostave kriterijume u pojedinačnim naukama, ali čiji je primarni cilj usmeren na to da se razume i interpretira živo meso sadašnjosti na temelju ovih struktura. On je time svakako otvorio put za nove filozofije budućnosti koje će se na različite načine nadovezati na ovu otvorenu metodologiju svesti. Iz njegovog ugla bismo mogli da zaključimo da nema budućnosti bez sadašnjosti, i da je primarni interes optimističnog karaktera usmeren na reafirmaciju prošlog $u$ cilju konstituisanja jedne bolje slike sveta.

\section{LITERATURA}

Biemel, Walter. Filozofijske analize moderne umjetnosti, prev. N. ČačinovićPuhovski, Prosveta, Zagreb, 1980.

Biemel, Walter. "La estética de Hegel." en: Convivium, 1962, pp. 147-162.

Ćipranić, Miloš. "Fantasmas mudos: una nota sobre la pintura." Escritura e Imagen 15 (2019): 345-355.

Erhard, Christopher. Denken über nichts - Intentionalität und nicht-existenz bei Husserl. Walter de Gryter GmbH, Berlin-Boston, 2014.

De Warren, Nicolas. "Towards a phenomenological analysis of virtual fictions." in: Metodo. International Studies in Phenomenology and Philosophy 2.2 (2014), pp. 91-112.

Gasset, José y Ortega. Dehumanizacija umetnosti i drugi eseji, LITTERIS, Zagreb, 2007.

Gasset, José y Ortega. La rebelión de las masas. Espasa-Calpe, Madrid, 1964.

Gasset, José y Ortega. Sobre el punto de vista en las artes. Revista de Occidente, Madrid, 1929.

Hartman, Nikolaj. Estetika, Dereta, Beograd, 2004.

Husserl, Edmund. Analyses concerning passive and active synthesis: Lectures on transcendental logic, Kluwer Academic Publishers, DordrechtBoston-London, 2001.

Husserl, Emdund. Erste Philosophie, Felix Meiner Verlag Hamburg, 1992. 
Husserl, Edmund. 1976. Ideen zu einer reinen Phänomenologie und phänomenologischen Philosophie. Erste Buch. Allgemeine Einführung in die reine Phänomenologie. Husserliana III/1. Edited by Karl Schuhmann. The Hague: Martinus Nijhoff. Translated by F. Kersten as Ideas Pertaining to a Pure Phenomenology and to a Phenomenological Philosophy, in Edmund Husserl Collected Works, vol. II (The Hague: Martinus Nijhoff, 1983). [HuaIII/1]

Husserl, Edmund, Phantasie, Bildbewusstsein, Erinnerung Zur Phänomenologie der Anschaulichen Vergegenwärtigungen. The Hague - Boston London: Martinus Nijhoff Publishers, 1980.

Husserl, Edmund. Philosophie als strenge Wissenschaft. Vittorio Clostermann, Frankfurt am Main, 1965.

Huserl, Edmund. Kartezijanske meditacije, prev. Prole D., Izdavačka knjižarnica Zorana Stojanovića, Sremski Karlovci - Novi Sad, 2020.

Kafka, Franz. „A Hunger Artist“, in: The Complete Stories, Schocken Books Inc., New-York, 1971.

Katz, Azul Tamina. "Toward a Husserlian Foundation of Aesthetics: On Imagination, Phantasy, and Image Consciousness in the 1904/1905 Lectures." in: The Journal of Speculative Philosophy 30.3 (2016), pp. 339-351.

Prole, Dragan. Jednakost nejednakog, Izdavačka knjižarnica Zorana Stojanovića, Sremski Karlovci-Novi Sad, 2018.

Prole, Dragan. "Redukcija u fenomenologiji i slikarstvu." Годишъак Филозофског факултета у Новом Саду 41.2 (2016): 67-77.

Rancière, Jacques. Aesthetics and its Discontents, Polity Press, Cambridge, 2009.

Rancière, Jacques. The future of the image. Verso, 2019.

Todorović, Tanja. „Fantazija i stvaralaštvo u Gasetovoj filozofiji“, u: Arhe 17.33 (2020): 221-242. 
TANJA TODOROVIĆ

University of Novi Sad, Faculty of Philosophy

\title{
THE AESTHETIC ROLE OF PHANTASY AND THE NEW STATUS OF IMAGE IN HUSSERL'S PHILOSOPHY
}

\begin{abstract}
For Husserl, the notion of phantasy has manifold roles. The aesthetic role of phantasy is only one of its functions, which is examined in the transcendental analysis of pure consciousness. Husserl in his analyses compares imagination and phantasy. Therefore, he avoids the traditional notion of imagination, Einbildungskraft, and uses the term Phantasie instead. A new understanding of the mediating role of the image in the perceptual and representational structures of consciousness can enable this difference. Husserl has never developed aesthetic theory systemically, although through a new transcendental-phenomenological position, he has shown a special place of aesthetic reflection in the structure of consciousness. He emphasize that phantasy apprehension is different from perceptual and representational modes of consciousness, which opens a new field for aesthetic as a free regime. This enables the traditional idea of dialectics to evolve in a new direction and builds a methodological foundation for a structuralism analysis of the phenomenon of image and body.
\end{abstract}

Keywords: aesthetic,body, phantasy, imagination, image, structuralism, transcendental-phenomenology

Primljeno: 7.6.2021.

Prihvaćeno: 8.8.2021. 
